\title{
A Reply to the Questions Regarding to the Article 'Effect of Lumbar Stabilization and Dynamic Lumbar Strengthening Exercises in Patients With Chronic Low Back Pain'
}

\author{
Hye Jin Moon, MD, Kyoung Hyo Choi, MD, PhD, Dae Ha Kim, MD, Ha Jeong Kim, MD, \\ Young Ki Cho, PT, MSc, Kwang Hee Leem, PT, BHSc, Jung Hoo Kim, PT, BSc, Yoo Jung Choi, PT, BHSc
}

Department of Rehabilitation Medicine, Asan Medical Center, University of Ulsan College of Medicine, Seoul, Korea

We appreciate your interest in our study.

In this study, we did not focus on lumbar extensor strength. Our interventions were consisted of trunk extensor, flexor, and rotator muscles strength. Isolated lumbar extensor strengthening machine MedX (MedX Holdings Inc., Ocala, FL, USA) was used to compare superficial muscles of trunk and deep spinal muscles strength between baseline and post-intervention.

You pointed out the similarities between lumbar stabilization and dynamic lumbar strengthening exercises. In exercise method of the two groups, the posture was somewhat similar on the picture. But in the text, we described that "before each exercise, the physical therapist gave detailed verbal explanation and visual instructions, regarding the start and end positions." All exercises were

Corresponding author: Kyoung Hyo Choi

Department of Rehabilitation Medicine, Asan Medical Center, University of Ulsan College of Medicine, 88 Olympic-ro 43-gil, Songpa-gu, Seoul 138-736, Korea.

Tel: +82-2-3010-3800, Fax: +82-2-3010-6964, E-mail: khchoi@amc.seoul.kr

(c) This is an open-access article distributed under the terms of the Creative Commons Attribution Non-Commercial License (http://creativecommons. org/licenses/by-nc/3.0) which permits unrestricted noncommercial use, distribution, and reproduction in any medium, provided the original work is properly cited.

Copyright $\odot 2014$ by Korean Academy of Rehabilitation Medicine conducted according to the following specific principles: "breathe in and out, gently and slowly draw in your lower abdomen below your umbilicus without moving your upper stomach, back or pelvis". In addition, the group of lumbar stabilization exercises subjects practiced 'abdominal hollowing maneuver' with a therapist providing verbal instruction and tactile feedback until they were able to perform the maneuver in a satisfactory manner $[1,2]$.

We thought that lumbar stabilization exercises should include strengthening deep lumbar muscles as well as neuromuscular control and endurance of these muscles. Conventional lumbar dynamic strengthening exercises were practiced to activate the erector spinae and rectus abdominis muscles.

You mentioned that the floor and ball based exercises had little evidence in conditioning effect of lumbar extensor muscles. However, floor- and ball-based exercises are commonly referred to as lumbar stability exercises in many studies $[3,4]$.

I would like to answer your question as follows:

1) Can exercises other than isolated lumbar extension (ILEX) condition the lumbar extensors (e.g., improve ILEX strength) in symptomatic participants, 
2) Does ILEX provide greater improvements in ILEX strength, pain and disability than other exercises in symptomatic participants?

At present, there is no study that has compared specific isolated lumbar extension training and lumbar stabilization exercise directly. Therefore, it is difficult to say which exercise method is more effective. In my opinion, lumbar extensor strengthening exercise is the most appropriate exercise for chronic LBP. That is why the study of Nachemson and Linch [5] showed that strengthening exercise on lumbar extensor increased the muscle activity, but increased loading of compression on the low back affects injury of tissue. It can cause pain and deteriorate the symptom. Some researchers demonstrated that traditional exercise methods on the deficiencies of stabilizer muscles can make an incorrect compensation. It also has effect on changes of proper muscle coordination pattern and recurrence $[6,7]$. However, the pathogenic mechanism of back pain is not ensuring. In addition, the effect of exercise treatment showed various results according to the study. Generally, clinical guidelines recommend exercise treatment rather than rest.

Today, exercise programs designed to improve lumbar stability and core strengthening are popular to increase athletic performance and treat pain. Movement patterns that were altered by faulty strength and flexibility, fatigue from poor endurance, and abnormal neural control would eventually cause tissue damage. Tissue damage would lead to decreased stability of spinal structures, increased challenges to the already inefficient muscles and the perpetuation of a degenerative cascade. Spinal stability could be compromised by motor control errors or poor muscular endurance of inter segmental muscles and allow for overloading of passive tissues. Patients with back pain also seem to over-activate superficial global muscles whereas control and activation of the deep spinal muscles is impaired. Thus, core stability exercises have strong theoretical basis for prevention of different musculoskeletal conditions and the treatment of spinal disorders [8]. Although a great deal of research has shown that exercises in general are effective treatment for lower back pain, much more research is needed that specifically addresses if lumbar stabilization exercises are more effective than other types of exercise in treating back pain.

3) Whether there is indeed any relationship between improved ILEX strength as a result of exercise interventions and changes in pain and disability.

I think that improvement of ILEX strength is contributing to the decrease of pain and disability. The optimal treatment for chronic low back pain is to provide ILEX training and superficial global muscles of trunk and deep spinal muscle strength exercises considering of individual physical characteristics.

\section{REFERENCES}

1. Richardson CA, Jull GA. Muscle control-pain control. What exercises would you prescribe? Man Ther 1995;1:2-10.

2. Hebert JJ, Koppenhaver SL, Teyhen DS, Walker BF, Fritz JM. The evaluation of lumbar multifidus muscle function via palpation: reliability and validity of a new clinical test. Spine J 2013 Oct 4 [Epub]. http://dx.doi. org/10.1016/j.spinee.2013.08.056.

3. Chung S, Lee J, Yoon J. Effects of stabilization exercise using a ball on mutifidus cross-sectional area in patients with chronic low back pain. J Sports Sci Med 2013;12:533-41.

4. Puntumetakul R, Areeudomwong P, Emasithi A, Yamauchi J. Effect of 10-week core stabilization exercise training and detraining on pain-related outcomes in patients with clinical lumbar instability. Patient Prefer Adherence 2013;7:1189-99.

5. Nachemson A, Lindh M. Measurement of abdominal and back muscle strength with and without low back pain. Scand J Rehabil Med 1969;1:60-3.

6. Richardson C, Jull G, Hodges P, Hides J. Local muscle dysfunction in low back pain. In: Richardson $\mathrm{C}$, editor. Therapeutic exercise for spinal segmental stabilization in low back pain: scientific basis and clinical approach. Edinburgh: Churchill Livingstone; 1999. p. 61-76.

7. Cholewicki J, McGill SM. Mechanical stability of the in vivo lumbar spine: implications for injury and chronic low back pain. Clin Biomech (Bristol, Avon) 1996;11:1-15.

8. Akuthota V, Ferreiro A, Moore T, Fredericson M. Core stability exercise principles. Curr Sports Med Rep 2008;7:39-44. 